\title{
CCL2/CCR2 signaling elicits itch- and pain-like behavior in a murine model of allergic contact dermatitis
}

Haowu Jiang ${ }^{\mathrm{a}, \mathrm{b}, 1}$, Huan Cui ${ }^{\mathrm{b}, 1}$, Tao Wang $^{\mathrm{b}}$, Steven G. Shimada ${ }^{\mathrm{a}}$, Rui Sun ${ }^{\mathrm{c}}$, Zhiyong Tan ${ }^{\mathrm{d}}$ Chao Ma ${ }^{\mathrm{b}} *$ and Robert H. LaMotte $\mathrm{a}^{\mathrm{a}, *}$

${ }^{a}$ Department of Anesthesiology, Yale University School of Medicine, New Haven, CT 06510, USA.

${ }^{b}$ Department of Anatomy, Histology and Embryology, Institute of Basic Medical Sciences,

Neuroscience Center, Chinese Academy of Medical Sciences, School of Basic Medicine,

Peking Union Medical College, Beijing 100005, China.

${ }^{c}$ Department of Internal Medicine, Section of Digestive Diseases, Yale University, New Haven, Connecticut 06510, USA.

${ }^{d}$ Department of Pharmacology and Toxicology and Stark Neurosciences Research Institute, Indiana University School of Medicine, Indianapolis, IN 46202, USA.

${ }^{1}$ These authors contributed equally to this work.

*Corresponding author:

Robert H. LaMotte, E-mail address: robert.lamotte@yale.edu.

Chao Ma, E-mail address: machao@ibms.cams.cn

\begin{abstract}
Spontaneous itch and pain are the most common symptoms in various skin diseases, including allergic contact dermatitis (ACD). The chemokine (C-C motif) ligand 2 (CCL2, also referred to as monocyte chemoattractant protein 1 (MCP-1))and its receptor CCR2 are
\end{abstract}


involved in the pathophysiology of ACD, but little is known of the role of CCL2/CCR2 for the itch- and pain-behaviors accompanying the murine model of this disorder, termed contact hypersensitivity (CHS). C57BL/6 mice previously sensitized to the hapten, squaric acid dibutyl ester, applied to the abdomen were subsequently challenged twice with the hapten delivered to either the cheek or to the hairy skin of the hind paw resulting in CHS at that site. By $24 \mathrm{~h}$ after the $2^{\text {nd }}$ challenge to the hind paw CCL2 and CCR2 mRNA, protein, and signaling activity were upregulated in the dorsal root ganglion (DRG). Calcium imaging and whole-cell current-clamp recordings revealed that CCL2 directly acted on its neuronal receptor, CCR2 to activate a subset of small-diameter, nociceptive-like DRG neurons retrogradely labeled from the CHS site. Intradermal injection of CCL2 into the site of CHS on the cheek evoked site-directed itch- and pain-like behaviors which could be attenuated by prior delivery of an antagonist of CCR2. In contrast, CCL2 failed to elicit either type of behavior in control mice. Results are consistent with the hypothesis that CHS upregulates CCL2/CCR2 signaling in a subpopulation of cutaneous small diameter DRG neurons and that CCL2 can activate these neurons through neuronal CCR2 to elicit itch- and pain-behavior. Targeting the CCL2/CCR2 signaling might be beneficial for the treatment of the itch and pain sensations accompanying ACD in humans.

Keywords: itch, pain, chemokine, dorsal root ganglion, allergic contact dermatitis

\section{Introduction}

Allergic contact dermatitis (ACD) is one of the most common inflammatory diseases of 
the skin, as a hapten-induced type IV delayed hypersensitivity reaction, which is primarily mediated by dermal dendritic cells (DC) and T lymphocytes, involving multiple cytokines and chemokines(Christensen and Haase, 2012; Grabbe and Schwarz, 1998; Honda et al., 2013; Sebastiani et al., 2002).

The chemokine (C-C motif) ligand 2 (CCL2), a member of the C-C chemokine subfamily, is a potent attractant of memory T-cells(Carr et al., 1994; Loetscher et al., 1994), monocytes(Deshmane et al., 2009) and natural killer (NK) cells(Allavena et al., 1994). CCL2 is involved in the pathophysiology of ACD in humans and the murine model of ACD, termed contact hypersensitivity (CHS). During the elicitation phase of ACD or CHS, CCL2 is the initial chemokine produced by activated resident skin cells such as keratinocytes, fibroblasts and endothelial cells preceding the infiltration of monocytes and lymphocytes. The infiltrating monocytes also serve as a secondary source of the chemokine(Goebeler et al., 2001; Mitsui et al., 2003; Sebastiani et al., 2002; Yu et al., 1994). Transgenic mice with an increased expression of CCL2 exhibited enhanced inflammatory responses during CHS together with more infiltration of dendritic cells into the skin(Mizumoto et al., 2001; Nakamura et al., 1995). In contrast, a downregulation of CCL2 using the RNA interference strategy attenuated hapten-induced CHS(Ishimoto et al., 2008).

Itch- and pain-related behaviors often accompany various skin diseases, including ACD in humans and CHS in mice(Buddenkotte and Steinhoff, 2010; LaMotte, 2016). Although the immune mechanisms of CHS have been intensively investigated, less is known of the itch and pain behaviors and their underlying neural mechanisms. CHS enhanced the excitability of cutaneous primary sensory neurons that mediate itch and pain(Qu et al., 2014). In addition, 
an associated upregulation of the chemokine receptor, CXCR3 in cutaneous neurons and responses to its ligand, CXCL10, suggested that this chemokine may contribute to itch associated with CHS(Qu et al., 2015).

Though CCL2 and its receptor CCR2 are typically expressed in immune cells, both can be upregulated in sensory neurons in models of chronic neuropathic or inflammatory pain(Abbadie et al., 2003; Illias et al., 2018; Jung et al., 2008; Serrano et al., 2010; Sun et al., 2006; Takeda et al., 2018; Tanaka et al., 2004; Thacker et al., 2009; White et al., 2005). Moreover, CCL2 can directly activate primary sensory neurons through neuronal CCR2 to exert its nociceptive effects(Serrano et al., 2010; Sun et al., 2006; Takeda et al., 2018; White et al., 2005). Although CCL2 plays an important role in the pathogenesis of ACD, a possible contribution of CCL2 to the itch- and pain-behaviors that accompany ACD has not been investigated.

In the present study, we tested the direct effects of CCL2 on primary sensory neurons and explored the potential role of CCL2/CCR2 signaling in mediating allergic itch and pain using a murine model of ACD induced by the hapten, squaric acid dibutylester (SADBE).

\section{Material and methods}

\subsection{Animals}

The mice used in the study were C57BL/6 males, 2 to 3 months of age and weighing 20-30 g. The breeders used to develop our colonies of MRGPRA3 and MRGPRD transgenic mice were provided by Dr Xinzhong Dong’s laboratory (John Hopkins University). For one 
type of mouse, the green fluorescent protein (GFP) was in neurons that expressed the MRGPRA3 receptor (MrgprA3 ${ }^{+}$neurons)(Han et al., 2013b) whereas the other type of mouse exhibited the GFP in neurons that expressed the MRGPRD receptor (MrgprD ${ }^{+}$ neurons)(Zylka et al., 2005). The experimental procedures were approved by the Institutional Animal Care and Use Committee of Yale University School of Medicine and were in accordance with the guidelines provided by the National Institute of Health and the International Association for the Study of Pain.

\subsection{Model of allergic contact dermatitis}

The mouse model of allergic contact dermatitis or CHS was elicited by the contact sensitizer squaric acid dibutylester (SADBE; Sigma, St. Louis, MO, USA)(Qu et al., 2014; Qu et al., 2015). "CHS" mice were first sensitized with $1 \%$ SADBE in acetone $(25 \mu \mathrm{L})$ topically applied to the shaved abdomen once a day for three consecutive days. Five days later, mice were challenged with two daily applications of $1 \%$ SADBE in acetone $(25 \mu \mathrm{L})$ either to the right cheek (cheek model for behavioral tests) or to the hairy skin of the calf and foot of one hind limb (calf model for in-vitro studies). Control mice received only acetone.

\subsection{Behavioral testing}

All behavioral tests were performed 24 hours after the second challenge with SADBE or acetone vehicle topically applied to the right cheek. The test chamber was equipped with four mirrors to provide a top view of all sides. Behavioral responses were video recorded by a camcorder. The video recording was subsequently played back offline in slow-motion to assess detailed measurements of scratching with the hind paw and wiping with the fore paw 
directed toward the challenge site. The total number of spontaneous scratching bouts and number of wipes were measured for 30 minutes(Shimada and LaMotte, 2008a). CCL2 (1 $\mu \mathrm{g} / 10 \mu \mathrm{L}$ in PBS; R\&D Systems, Minneapolis, MN, USA) or its vehicle alone (10 $\mu \mathrm{L}$ PBS) was injected intradermally into the right cheek in CHS mice and control mice. In some experiments, a highly selective CCR2 chemokine receptor antagonist RS504393 (5 mg/kg; R\&D Systems) or its vehicle alone (DMSO) was injected intraperitoneally 30 min before the cheek injection of CCL2 in CHS mice(Miller et al., 2012). Each chemical injected was previously prepared and then coded by a laboratory assistant and not the experimenter. The experimenter who injected the chemical was blinded to the code and thus the chemical injected, as was the observer who scored the video-recorded behavior.

\subsection{Reverse transcription and quantitative RT-PCR}

Ipsilateral L3 to L5 lumbar DRG were harvested 24 hours after the second challenge in CHS mice and in acetone treated controls and flash-frozen in liquid nitrogen. Total RNAs were extracted using Trizol reagent (Invitrogen, Grand Island, NY, USA) and reverse transcribed using PrimeScript ${ }^{\mathrm{TM}}$ RT Master Mix (Takara, Japan) according to the manufacturer's instructions. Quantitative RT-PCR (qRT-PCR) was performed on a Bio-Rad CFX96 machine using SYBR Premix Ex Taq (Takara, Japan). The primers used were as follows: CCL2 forward, 5'-AGG TCC CTG TCA TGC TTC TG-3' and reverse, 5'- TCA TTG GGA TCA TCT TGC TG -3'(Kiguchi et al., 2013); CCR2 forward, 5'-CTC AGT TCA TCC ACG GCA TA-3' and reverse, 5'- CAA GGC TCA CCA TCA TCG TA -3'(Kiguchi et al., 2013); GAPDH forward, 5'-CCA TGA CAA CTT TGG CAT TG -3' and reverse, 5'-CCT GCT TCA CCA CCT TCT TG -3'. The expression levels of the target genes were quantified 
relative to the level of GAPDH gene expression using the $2^{-\Delta \Delta C T}$ method. Real-time PCR experiments for each gene were performed on three separate occasions.

\subsection{Western blotting}

Ipsilateral L3 to L5 lumbar DRG, tissue samples of hairy skin of the calf (calf model) and TG (cheek model) were harvested 24 hours after the second challenge in CHS mice and in acetone treated controls and then homogenized in the RIPA lysis buffer (CWBio, Beijing, China) containing a mixture of protease inhibitors (CWBio). The protein concentrations of the lysate were measured using a PierceTM BCA Protein Assay kit (Thermo Scientific, Rockford, IL, USA). Equal amounts of protein samples were loaded and separated in 12\% SDS-PAGE gel and subsequently transferred to PVDF membranes (GE Healthcare, Pittsburgh, PA, USA). After blocked in PBST with 5\% nonfat dry milk for $2 \mathrm{~h}$ at room temperature, the membranes were incubated overnight at $4^{\circ} \mathrm{C}$ with mouse-anti-CCL2 $(1: 1000$, Millipore, Burlington, MA, USA), rabbit-anti-CCR2 (1:1000, Abcam, Cambridge, MA, USA) or mouse-anti-GAPDH (1:1000, ZSGB-Bio, Beijing, China) primary antibodies. The membranes were then incubated with HRP-conjugated goat anti-mouse (1:3000, ZSGB-Bio) or HRP-conjugated goat anti-rabbit (1:3000, ZSGB-Bio) secondary antibodies for $1 \mathrm{~h}$ at room temperature. Signals were finally detected using eECL Western Blot Kit (CWBio), and the bands were visualized with the Amersham Imager 600 (GE Healthcare, Pittsburgh, PA, USA).

\subsection{Immunohistochemistry}

Immunofluorescent labeling was performed on DRGs (calf model) and TGs (cheek model) from 3 acetone treated control mice and 3 SADBE treated CHS mice (24 hours after the 
second challenge) using the method described previously(Jiang et al., 2017; Liu et al., 2017): Briefly, the L3 to L5 DRGs and TGs were harvested from control and CHS mice transcardially perfused with PBS followed by $4 \%$ paraformaldehyde, post-fixed in the same fixative for $2 \mathrm{~h}$, and then cryoprotected in $30 \%$ sucrose overnight. The tissue was frozen and sectioned at $12 \mu \mathrm{m}$ thick on a cryostat. Tissue sections were permeabilized with $0.2 \%$ Triton X-100 in PBS for 15 min, then incubated with blocking buffer (10\% normal horse serum) for $1 \mathrm{~h}$, followed by overnight incubation at $4^{\circ} \mathrm{C}$ with primary antibodies (mouse-anti-CCL2, 1:200, Millipore; rabbit-anti-CCR2, 1:200, Abcam; guinea pig anti-PGP9.5, 1:400, Abcam; guinea pig anti-TRPV1, 1:400, Abcam) and then with the proper secondary antibodies (Alexa Fluor 488-conjugated donkey anti-mouse, 1:400; Alexa Fluor 488-conjugated donkey anti-rabbit, 1:400; Alexa Fluor 594-conjugated donkey anti-guinea pig, 1:400, Invitrogen) for 1 h. Alexa Fluor 594-conjugated IB4 (1:400, Invitrogen) was added with the secondary antibodies. The slides were then washed in PBS and cover-slipped with VECTASHIELD Mounting Medium with DAPI (Vector Laboratories, Burlingame, CA, USA). The cells were visualized and the images were captured using a laser confocal microscopic imaging system (FV1000 and Olympus FluoView software, Olympus, Japan). Here, the dissociated DRG and TG neurons in adult mice are categorized into small- $(10-25 \mu \mathrm{m})$, medium- $(25-35 \mu \mathrm{m})$ and large-sized $(>35 \mu \mathrm{m})$ based on somal diameter. After taking into account the approximately $10 \%$ decrease in size because of the fixation procedure, DRG and TG neurons were classified as small- (area $<442 \mu \mathrm{m}^{2}$ ), medium- (area 443-865 $\mu \mathrm{m}^{2}$ ) and large-sized (area $>865 \mu \mathrm{m}^{2}$ ) according to their cross-sectional areas. Only neurons with nucleus profile in the cross-section were counted and data from L3 to L5 DRGs were pooled throughout the study. 


\subsection{Retrograde labeling of cutaneous neurons}

For the in vitro experiments, DiI (Invitrogen), a red fluorescent dye, was injected intradermally at a dose of $1.7 \mathrm{mg} / \mathrm{mL}$ in $1 \%$ DMSO into the hairy skin of the calf and foot of one hind limb of mice at 3 sites $(10 \mu \mathrm{L}$ per site $)$ at least 1 week before the first challenge with SADBE or acetone vehicle. The label was retrogradely transported to the DRG and subsequently used to identify small-diameter, cutaneous DRG neurons innervating the area of CHS (or vehicle treatment).

\subsection{Acute culture of dorsal root ganglion neurons}

DRG neurons were acutely cultured as previously described(Qu et al., 2015). Briefly, L3 to L5 lumbar DRG, ipsilateral to either acetone control or SADBE-treated skin, were harvested from mice $24 \mathrm{~h}$ after the second SADBE challenge or application of acetone vehicle and placed in oxygenated complete saline solution (CSS) for cleaning and mincing. The CSS contained (mM): $137 \mathrm{NaCl}, 5.3 \mathrm{KCl}, 1 \mathrm{MgCl}_{2}, 3 \mathrm{CaCl}_{2}, 25$ sorbitol, and $10 \mathrm{HEPES}$, adjusted to $\mathrm{pH} 7.2$ with $\mathrm{NaOH}$. The DRG were then digested with Liberase TM $(0.35 \mathrm{U} / \mathrm{ml}$; Roche Diagnostics Corp., Indianapolis, IN, USA) for $20 \mathrm{~min}$, and for another $15 \mathrm{~min}$ with Liberase TL (0.25 U/ml; Roche Diagnostics Corp.) and papain ((30 U/mL; Worthington Biochemical, Lakewood, NJ, USA) in CSS containing $0.5 \mathrm{mM}$ EDTA at $37{ }^{\circ} \mathrm{C}$. After enzymatic digestion, the cells were dissociated by gentle trituration in DMEM medium containing $1 \mathrm{mg} / \mathrm{ml}$ bovine serum albumin (Sigma) and $1 \mathrm{mg} / \mathrm{ml}$ trypsin inhibitor (Sigma), and placed on poly-D-lysine/laminin coated glass coverslips (BioCoat; BD Biosciences, San Jose, CA, USA). The DMEM medium contained equal amounts of DMEM and F12 (Gibco, 
Grand Island, MD, USA) with 10\% FCS (Gibco) and $1 \%$ penicillin and streptomycin (Invitrogen). The cells were maintained at $37{ }^{\circ} \mathrm{C}$ in a humidified incubator of $95 \%$ air and $5 \%$ $\mathrm{CO} 2$ and used within $24 \mathrm{~h}$.

\subsection{Calcium imaging}

Calcium imaging was performed on the small-diameter $(\leq 25 \mu \mathrm{m})$ DiI-labeled DRG neurons as described previously(Qu et al., 2015; Qu et al., 2011b). Briefly, DRG neurons were loaded with $2 \mu \mathrm{M}$ Fura 2-acetoxymethyl ester (Invitrogen) in the dark at $37{ }^{\circ} \mathrm{C}$. After loading for 45 min, DRG neurons were washed twice with a HEPES buffer to remove extracellular dye. The HEPES buffer contained the following (in $\mathrm{mM}$ ): $\mathrm{NaCl} \mathrm{145,} \mathrm{KCl} 3$, $\mathrm{CaCl}_{2} 2, \mathrm{MgCl}_{2}$ 2, glucose 10 and HEPES 10, adjusted to $\mathrm{pH} 7.4$ with $\mathrm{NaOH}$. In some experiments, DRG neurons were then incubated with $10 \mu \mathrm{g} / \mathrm{mL}$ isolectin B4 conjugated to fluorescein isothiocyanate (IB4-FITC; Sigma) for $10 \mathrm{~min}$, washed in HEPES buffer, and visualized with FITC filters. Only neurons with a complete ring of FITC stain around the perimeter of the soma were considered as IB4-positive neurons $\left(\mathrm{IB}^{+}{ }^{+}\right)$. Ratiometric calcium imaging was performed at room temperature of 20 to $22^{\circ} \mathrm{C}$ using an upright Olympus BX-51WI microscope equipped with a ratiometric imaging system (INDEC Biosystems, CA, USA). The calcium signals by 340 and $380 \mathrm{~nm}$ excitation (switched by the monochromator, Polychrome V, TILL Photonics, Hillsboro, OR) were recorded at 2-s intervals using a cooled CCD camera (SensiCAM, PCO, Germany) controlled by a computer with Image Workbench 5.2 software (INDEC Biosystems, CA, USA). The ratio of $340 \mathrm{~nm} / 380 \mathrm{~nm}$ fluorescence intensity $\left(\mathrm{R}_{340} / 380\right)$ within a certain region of interest was used as a relative measure of intracellular calcium concentration $\left(\left[\mathrm{Ca}^{2+}\right]_{\mathrm{i}}\right)($ Grynkiewicz et al., 1985). All agents were 
dissolved in HEPES buffer and applied locally to the neuronal cell bodies through a micropipette with a tip diameter of $100 \mu \mathrm{m}$ and a 8-channel pressure-controlled drug application system (AutoMate Scientific, Berkeley, CA, USA). Mouse recombinant CCL2 (50 $\mathrm{nM})(\mathrm{Oh}$ et al., 2001) or RS504393 (10 $\mu \mathrm{M}$ in 0.1\% DMSO) (Mirzadegan et al., 2000; Zhou et al., 2011)was added to HEPES buffer. Histamine (His; $100 \mu \mathrm{M} ; 30$ s) or capsaicin (CAP; $1 \mu \mathrm{M} ; 10 \mathrm{~s}$ ), was applied to identify His- and CAP-sensitive nociceptors, respectively. At the end of each experiment, the viability of the neurons was confirmed by the increase in $\left[\mathrm{Ca}^{2+}\right]_{\mathrm{i}}$ induced by a $5 \mathrm{~s}$ application of $50 \mathrm{mM} \mathrm{K}$. Neurons were considered to respond to a chemical if an increase in $\left[\mathrm{R}_{(340 / 380)}\right]$ was equal or greater than $15 \%$ above baseline(Wilson et al., 2011). The proportion of DRG neurons responsive to a chemical was calculated as the number of chemically-responsive neurons divided by all the neurons tested. Only Dil-labeled cutaneous small-diameter neurons $(\leq 25 \mu \mathrm{m})$ that innervated the chemically treated areas were used. In transgenic mice, MRGPRA $3^{+}$and $\mathrm{MRGPRD}^{+}$neurons that innervated the epidermis were additionally labeled by a GFP(Han et al., 2013b; Qu et al., 2014).

\subsection{Whole-cell patch-clamp recordings}

Whole-cell current-clamp recordings were made on small-diameter $(\leq 25 \mu \mathrm{m})$ DiI-labeled DRG neurons using a MultiClamp 700A amplifier and pCLAMP 9 software (Molecular Devices, Sunnyvale, CA, USA), as described(Qu et al., 2011a; Qu et al., 2015; Qu et al., 2012). Signals were sampled at $10 \mathrm{kHz}$ or $20 \mathrm{kHz}$ and filtered at $2 \mathrm{kHz}$. The patch pipettes were pulled from borosilicate glass capillaries (Sutter Instruments, Novato, CA, USA; 1.2 $\mathrm{mm}$ outer diameter, $0.69 \mathrm{~mm}$ inner diameter) with a P97 horizontal puller (Sutter Instruments). The resistance of the patch pipettes was 3-4 M $\Omega$ after filled with an internal 
solution, the liquid junction potentials were corrected and the series resistance was routinely compensated at $60 \%$ to $80 \%$. The internal solution contained the following (in $\mathrm{mM}$ ): $\mathrm{K}^{+}$-gluconate $120, \mathrm{KCl} 30, \mathrm{MgCl}_{2} \cdot 6 \mathrm{H}_{2} \mathrm{O} 2$, HEPES 10, MgATP $2, \mathrm{CaCl}_{2} \cdot 2 \mathrm{H}_{2} \mathrm{O}$ 1, EGTA 11 , with an osmolarity of 290-300 mOsm and a pH that was adjusted to 7.2 using Tris base. The DRG neurons were continuously perfused with the HEPES buffer and all the recordings were performed at a room temperature of $20-22{ }^{\circ} \mathrm{C}$. The resting membrane potential (RMP) of each neuron was recorded after stabilization within $3 \mathrm{~min}$. A neuron was studied only if its RMP was more negative than $-45 \mathrm{mV}$. Action potentials (APs) were evoked by a series of depolarizing current steps, each of $500 \mathrm{~ms}$ duration, in increments of $50 \mathrm{pA}$ up to $1 \mathrm{nA}$. The current threshold (rheobase) was defined as the minimal depolarizing current required to evoke an AP. The input resistance was obtained from the slope of a steady-state current-voltage plot in response to a series of hyperpolarizing currents steps from -200 to -50 pA, each step $500 \mathrm{~ms}$ in duration.

\subsection{Statistical analyses}

Data values were presented as means \pm SEMs. Statistical analyses were performed using the SPSS software (version 17.0). A Student's t-test was used to test the statistical significance of a difference between mean responses for two groups. Chi-square tests were used to compare the incidence of neuronal responses. The criterion for statistical significance was a value of $p<0.05$.

\section{Results}




\subsection{CHS upregulated neuronal expression of CCL2 and CCR2}

The mean levels of mRNA expression for CCL2 and CCR2 were significantly greater in the DRG from CHS mice compared with those from control mice treated only with acetone (Fig. 1A). From analyses with Western blot, the protein levels of CCL2 and CCR2 were significantly upregulated in the DRG in CHS mice compared with that in control mice (Fig. 1B and C). Immunofluorescent staining revealed very few CCL2- and CCR2-immunopositive DRG neurons in control mice (Fig. 1D, G and H). In contrast, the mean percentage of CCL2and CCR2-immunopositive DRG neurons was significantly greater in CHS mice (Fig. 1D, I and J). Based on our categorizations of neuronal size (see Methods), $87.0 \%$ of CCL2-immunopositive DRG neurons after CHS were classified as small, $13.0 \%$ were medium, and none were large (Fig. 1E). CCR2 was found expressed in all size categories of DRG neurons in CHS mice with $76.3 \%$ of CCR2-immunopositive DRG neurons classified as small, $21.3 \%$ as medium and only $2.5 \%$ as large (Fig. E). In addition, some CCR2-immunopositive DRG neurons were also immunopositive for the nociceptive neuronal markers IB4 (detected in 55.8\% of neurons with CCR2-immunopositive, Fig. 1K) and TRPV1 (56.7.0\%, Fig. 1L).

3.2. CHS increased the incidence and magnitude of CCR2-mediated $\mathrm{Ca}^{2+}$ responses to

\section{CCL2 in cutaneous DRG neurons}

CCL2 (50 nM; $2 \mathrm{~min}$ ) applied locally to the neuronal cell bodies caused a $\left[\mathrm{Ca}^{2+}\right]_{\mathrm{i}}$ increase in few cutaneous DRG neurons from control mice (Fig. 2A, C). However, there were significantly more neurons responding to CCL2 in CHS mice (Fig. 2B, C). Furthermore, the mean magnitude of CCL2-evoked $\mathrm{Ca}^{2+}$ responses was significantly greater in neurons for 
CHS than control mice (Fig. 2D). Among CCL2-responsive neurons from CHS mice, 80.6\% (50 of 62 ) and $75.8 \%$ (47 of 62 ) responded to histamine (His, $100 \mu \mathrm{M}$ ) and capsaicin (CAP, 1 $\mu \mathrm{M})$ with an increase in $\left[\mathrm{Ca}^{2+}\right]_{\mathrm{i}}$, respectively (Fig. $2 \mathrm{~B}$ ). When the neurons incubated with 10 $\mu \mathrm{g} / \mathrm{mL}$ IB4-FITC in HEPES buffer for $10 \mathrm{~min}, 71.4 \%$ (30 of 42) CCL2-responsive neurons were IB4 ${ }^{+}$.

MRGPRA3 $^{+}$and MRGPRD ${ }^{+}$neurons were previously found to contribute to pain- and/or itch-related behavior associated with CHS(Han et al., 2013b; Qu et al., 2014; Qu et al., 2015). Here we found that the percentage of CCL2-responsive cutaneous neurons genetically labeled as expressing MRGPRA3 ${ }^{+}$and MRGPRD ${ }^{+}$receptors (Fig. 2E, G) and the magnitude of their responses (Fig. 2F, H) were significantly greater in CHS than control mice. These data indicate that more MRGPRA3 ${ }^{+}$and $\mathrm{MRGPRD}^{+}$pruriceptive nociceptors express functional CCR2 receptors and can be directly activated by CCL2 after CHS.

To examine the role of neuronal CCR2 in the CCL2-evoked $\left[\mathrm{Ca}^{2+}\right]_{\mathrm{i}}$ responses, DRG neurons were pretreated with a specific CCR2 antagonist, RS504393 (10 $\mu \mathrm{M}$ in 0.1\% DMSO vehicle), for 3 min(Mirzadegan et al., 2000; Wang et al., 2010; Zhou et al., 2011). In the presence of RS504393, the percentage of CCL2-responsive neurons was significantly reduced compared with the effects of vehicle alone (Fig. 3A-C). Furthermore, the mean magnitude of CCL2-evoked $\mathrm{Ca}^{2+}$ responses was significantly attenuated by RS504393 but not by vehicle alone (Fig. 3D). These results suggest that neuronal CCR2 mediated the CCL2-induced $\left[\mathrm{Ca}^{2+}\right]_{\mathrm{i}}$ responses in DRG neurons.

\subsection{CCL2 increased the membrane excitability of dorsal root ganglion neurons innervating CHS skin through neuronal CCR2.}


Whole-cell current-clamp recordings were performed on DiI-labeled small-diameter DRG neurons from CHS mice and acetone-treated control mice. The local application of CCL2 (50 nM; 2 min) but not vehicle, depolarized more cutaneous DRG neurons (Fig. 4B, C and D) from CHS- than from control mice (Fig. 4B). Moreover, Four of 11 responsive neurons (36.3\%) from CHS mice exhibited action potential (AP) discharges (Fig. 4A). The local application of CCL2 significantly decreased the rheobase (Fig. 4F) and the input resistance (Fig. 4E), suggesting an increase in the opening of resting ion channels. Pretreatment with RS504393 $(10 \mu \mathrm{M})$ for 3 min decreased the percentage of CCL2-responsive neurons (Fig. 4H). Furthermore, in the presence of RS504393, the CCL2-induced membrane depolarization was significantly attenuated and no AP discharges was evoked for these responsive neurons (Fig. 4G, I). These results indicate that neuronal CCR2 mediates the direct excitatory effect of CCL2 on primary sensory neurons after CHS.

\subsection{CCL2 and CCR2 mediated itch- and pain-like behaviors in CHS mice.}

The cheek model was used to investigate the behavioral effects of CCL2 in CHS(Shimada and LaMotte, 2008b). Consistent with the expression pattern of DRG neurons in the calf model, CCR2 was significantly upregulated in TG neurons innervating the cheek (Fig. S1). At 24 hours after the second challenge, consistent with our previous studies(Qu et al., 2014; Qu et al., 2015), mice challenged with SADBE displayed a significant increase in the number of spontaneous site-directed bouts of scratching and number of wipes as compared with acetone-treated control mice (Fig. 5A and B). Intradermal injection of CCL2 (1 $\mu \mathrm{g} / 10 \mu \mathrm{l})$ into the cheek of CHS mice induced more scratching bouts and more wipes in comparison with the injection of vehicle (PBS) (Fig. 5A and B). In contrast, CCL2 injected into the acetone 
control cheek evoked the same amount of scratching and wiping as an injection of PBS vehicle alone (Fig. 5A and B). Moreover, intraperitoneal pre-injection of RS504393 (5 $\mathrm{mg} / \mathrm{kg}$ ), a highly selective CCR2 chemokine receptor antagonist, but not its vehicle (DMSO), completely inhibited the scratching and wiping evoked by CCL2 injected in CHS mice (Fig. 5B, D). These results suggest that CCL2 mediates itch and pain behaviors through CCR2 in vivo under inflammatory skin conditions.

\section{Discussion}

In this study, we first demonstrated that CHS upregulated CCL2/CCR2 signaling in cutaneous primary sensory neurons, that CCL2 could directly activate CCR2 expressed on cutaneous small-diameter primary sensory neurons, and that an injection of CCL2 into the CHS site evoked itch- and pain-like behaviors.

CCL2 and CCR2 are widely expressed in the immune system and not expressed at high levels in the normal nervous system. However, the synthesis of CCL2 and CCR2 can be significantly up-regulated in primary sensory neurons under pathological conditions(Abbadie et al., 2003; Bhangoo et al., 2007; Jeon et al., 2008; Jung et al., 2009; Tanaka et al., 2004; White et al., 2005; Zhang and De Koninck, 2006). For example, CCL2 and CCR2 are up-regulated in primary sensory neurons after a chronic compression of the DRG (CCD)(Sun et al., 2006; White et al., 2005). In the present study mRNA and protein expression levels of CCL2 and CCR2 were both significantly increased in DRG after the development of CHS. CCL2 was also significantly upregulated in the inflamed skin (Fig. S2) as found in previous studies and attributed to its release from activated resident skin cells and monocytes(Goebeler 
et al., 2001; Mitsui et al., 2003; Sebastiani et al., 2002; Yu et al., 1994). The present upregulation of neuronal CCL2 is consistent with the hypothesis that the chemokine may be released from the peripheral terminals of DRG neurons in the area of CHS.

There was a significantly greater percentage of primary sensory neurons expressing not only CCL2 but also CCR2 after CHS. Although CCR2 was found in all size categories of primary sensory neurons, it was mainly presented in small-diameter neurons as well as CCL2. Notably, the expression pattern of CCR2 in primary sensory neurons may be different in different types of pathology. In an animal model of Paclitaxel (chemotherapy-induced peripheral neuropathy), CCR2 was strongly upregulated in DRG neurons of large- and medium-size but not small size whereas CCL2 was mainly expressed in small nociceptive neurons(Zhang et al., 2013). In the present study, CCL2-responsive neurons had characteristics of nociceptors as evidenced by their expression of $\mathrm{IB}^{+}$and TRPV1 or their calcium responses to capsaicin. Some of the neurons responsive to CCL2 after CHS were pruriceptive nociceptors that expressed MRGPRA3 or MRGPRD. These neurons are known to respond to one or more pruritic chemicals such as chloroquine, histamine and BAM8-22 (MRGPRA3 ${ }^{+}$neurons)(Han et al., 2013b) or $\beta$-alanine (MRGPRD ${ }^{+}$neurons)(Liu et al., 2012). ACD (CHS) is an inflammatory skin disease orchestrated by proinflammatory mediators. Some of these mediators include cytokines that, under various conditions, activate transcription factors that increase in the synthesis of CCL2 and/or CCR2 in peripheral sensory neurons(Glabinski et al., 2003; Jung and Miller, 2008; Subang and Richardson, 2001; Tofaris et al., 2002; Ueda et al., 1994). CCL2 in DRG neurons is packaged into large dense-core vesicles (LDCVs) whose release could be induced from the soma by 
depolarization in a $\mathrm{Ca}^{2+}$-dependent manner(Jung et al., 2008). Possibly the presence of CCL2 in the DRG could result in the upregulation of TRPV1 and the voltage-gated sodium channel, Nav1.8(Kao et al., 2012). However, the mechanisms for the synthesis, release and effects of CCL2 in the DRG after CHS will require further investigation.

CCL2 depolarized and sometimes evoked action potentials discharge in neurons that innervated the site of CHS but rarely so in neurons that had innervated healthy, control skin. The ionic mechanisms underlying CCL2-induced neuronal activation have been well studied. CCL2 excites CCD-treated neurons through the activation of a non-voltage-dependent depolarizing current with characteristics similar to a nonselective cation conductance and through the inhibition of a voltage-dependent outward current(Sun et al., 2006). CCR2 is a G protein-coupled receptor. CCL2, binding to CCR2, leads to the activation of PLC, which is critical for the increase in intracellular calcium $\left(\left[\mathrm{Ca}^{2+}\right]_{\mathrm{i}}\right)($ White et al., 2005). Some studies reported that this activation of CCR2 by CCL2 could excite DRG neurons via transactivation of TRRV1 and TRPA1(Jung et al., 2008).

Previous studies have shown that CCL2 is involved in the pathogenesis of CHS, but not whether the chemokine contributes to the itch and pain that accompany this disorder. In the present study, we observed that an intradermal injection of CCL2 into the site of CHS significantly elicited site-directed itch- and pain-like behaviors. Neither type of CCL2-evoked behaviors was observed in control mice. In addition, the exogenous CCL2-evoked itch- and pain-like behaviors were almost abolished by an antagonist of CCR2. Itch and pain are normally initiated and mediated by primary nociceptive neurons. It is clear that CCL2 can directly activate primary nociceptors through neuronal CCR2 to elicit and/or maintain certain 
types of neuropathic or inflammatory pain(Miller et al., 2012; Serrano et al., 2010; Sun et al., 2006; Takeda et al., 2018; White et al., 2005). There was evidence that MrgprA3 ${ }^{+}$neurons were needed for normal histamine-dependent itch behavior(Han et al., 2013a), MrgprD ${ }^{+}$ neurons contribute to mechanically evoked pain but also to the histamine-independent itch evoked by $\beta$-alanine(Cavanaugh et al., 2009; Liu et al., 2012). Furthermore, both types of pruriceptive neurons displayed enhanced excitability after CHS(Qu et al., 2014). The present study from in vitro calcium imaging and electrophysiological recordings demonstrated that the activation of neuronal CCR 2 by CCL2 can directly excite cutaneous sensory neurons with nociceptive and pruriceptive properties. Therefore, our findings suggest that CCL2 directly activates neuronal CCR2 to induce itch- and pain-like behaviors in the context of CHS.

Because CCR2 is expressed in immune cells including macrophages, dendritic cells, $\mathrm{T}$ cells and NK cells, CCL2 binding to CCR2 in the peripheral tissue might indirectly activate primary sensory neurons through the release of proinflammatory cytokines from immune cells(Allavena et al., 1994; Carr et al., 1994; Loetscher et al., 1994). Furthermore, our previous study revealed that the upregulation of CXCL10/CXCR3 signaling in sensory neurons may contribute to itch associated with CHS(Qu et al., 2015). These chemokines may work together to contribute to the itch and pain accompanying CHS in mice and in humans by directly exciting primary sensory neurons through their neuronal receptors and/or indirectly activating immune cells to induce the release of inflammatory mediators that target primary sensory neurons.

\section{Conflict of interest statement}


The authors have no conflicts of interest to declare.

\section{Acknowledgements}

We thank Lintao Qu, Pu Zhang and Jennifer Yang for technical support. This study was supported by National Institute of Neurological Disorders and Stroke, Grant NS014624 (to R.

H. LaMotte) and by the China Scholarship Council (H. Jiang).

\section{References}

Abbadie, C., Lindia, J.A., Cumiskey, A.M., Peterson, L.B., Mudgett, J.S., Bayne, E.K., DeMartino, J.A., MacIntyre, D.E., Forrest, M.J., 2003. Impaired neuropathic pain responses in mice lacking the chemokine receptor CCR2. Proc Natl Acad Sci U S A 100, 7947-7952.

Allavena, P., Bianchi, G., Zhou, D., van Damme, J., Jilek, P., Sozzani, S., Mantovani, A., 1994. Induction of natural killer cell migration by monocyte chemotactic protein-1, -2 and -3 . European journal of immunology 24 , 3233-3236.

Bhangoo, S., Ren, D., Miller, R.J., Henry, K.J., Lineswala, J., Hamdouchi, C., Li, B., Monahan, P.E., Chan, D.M., Ripsch, M.S., White, F.A., 2007. Delayed functional expression of neuronal chemokine receptors following focal nerve demyelination in the rat: a mechanism for the development of chronic sensitization of peripheral nociceptors. Molecular pain 3, 38 .

Buddenkotte, J., Steinhoff, M., 2010. Pathophysiology and therapy of pruritus in allergic and atopic diseases. Allergy 65, 805-821.

Carr, M.W., Roth, S.J., Luther, E., Rose, S.S., Springer, T.A., 1994. Monocyte chemoattractant protein 1 acts as a T-lymphocyte chemoattractant. Proc Natl Acad Sci U S A 91, 3652-3656.

Cavanaugh, D.J., Lee, H., Lo, L., Shields, S.D., Zylka, M.J., Basbaum, A.I., Anderson, D.J., 2009. Distinct subsets of unmyelinated primary sensory fibers mediate behavioral responses to noxious thermal and mechanical stimuli. Proc Natl Acad Sci U S A 106, 9075-9080.

Christensen, A.D., Haase, C., 2012. Immunological mechanisms of contact hypersensitivity in mice. APMIS : acta pathologica, microbiologica, et immunologica Scandinavica 120, 1-27.

Deshmane, S.L., Kremlev, S., Amini, S., Sawaya, B.E., 2009. Monocyte chemoattractant protein-1 (MCP-1): an overview. Journal of interferon \& cytokine research : the official journal of the International Society for Interferon and Cytokine Research 29, 313-326.

Glabinski, A.R., Bielecki, B., Kolodziejski, P., Han, Y., Selmaj, K., Ransohoff, R.M., 2003. TNF-alpha microinjection upregulates chemokines and chemokine receptors in the central nervous system without inducing leukocyte infiltration. Journal of interferon \& cytokine research : the official journal of the International Society 
for Interferon and Cytokine Research 23, 457-466.

Goebeler, M., Trautmann, A., Voss, A., Brocker, E.V., Toksoy, A., Gillitzer, R., 2001. Differential and sequential expression of multiple chemokines during elicitation of allergic contact hypersensitivity. The American journal of pathology 158, 431-440.

Grabbe, S., Schwarz, T., 1998. Immunoregulatory mechanisms involved in elicitation of allergic contact hypersensitivity. Immunology today 19, 37-44.

Grynkiewicz, G., Poenie, M., Tsien, R.Y., 1985. A new generation of Ca2+ indicators with greatly improved fluorescence properties. The Journal of biological chemistry 260, 3440-3450.

Han, L., Ma, C., Liu, Q., Weng, H.J., Cui, Y., Tang, Z., Kim, Y., Nie, H., Qu, L., Patel, K.N., Li, Z., McNeil, B., He, S., Guan, Y., Xiao, B., Lamotte, R.H., Dong, X., 2013a. A subpopulation of nociceptors specifically linked to itch. Nat Neurosci 16, 174-182.

Han, L., Ma, C., Liu, Q., Weng, H.J., Cui, Y.Y., Tang, Z.X., Kim, Y.S., Nie, H., Qu, L.T., Patel, K.N., Li, Z., McNeil, B., He, S.Q., Guan, Y., Xiao, B., LaMotte, R.H., Dong, X.Z., 2013b. A subpopulation of nociceptors specifically linked to itch. Nat Neurosci 16, 174-182.

Honda, T., Egawa, G., Grabbe, S., Kabashima, K., 2013. Update of immune events in the murine contact hypersensitivity model: toward the understanding of allergic contact dermatitis. The Journal of investigative dermatology 133, 303-315.

Illias, A.M., Gist, A.C., Zhang, H., Kosturakis, A.K., Dougherty, P.M., 2018. Chemokine CCL2 and its receptor CCR2 in the dorsal root ganglion contribute to oxaliplatin-induced mechanical hypersensitivity. Pain 159, 1308-1316.

Ishimoto, T., Takei, Y., Yuzawa, Y., Hanai, K., Nagahara, S., Tarumi, Y., Matsuo, S., Kadomatsu, K., 2008. Downregulation of monocyte chemoattractant protein-1 involving short interfering RNA attenuates hapten-induced contact hypersensitivity. Molecular therapy : the journal of the American Society of Gene Therapy 16, 387-395.

Jeon, S.M., Lee, K.M., Park, E.S., Jeon, Y.H., Cho, H.J., 2008. Monocyte chemoattractant protein-1 immunoreactivity in sensory ganglia and hindpaw after adjuvant injection. Neuroreport 19, 183-186.

Jiang, H., Shen, X., Chen, Z., Liu, F., Wang, T., Xie, Y., Ma, C., 2017. Nociceptive neuronal Fc-gamma receptor I is involved in IgG immune complex induced pain in the rat. Brain Behav Immun 62, 351-361.

Jung, H., Bhangoo, S., Banisadr, G., Freitag, C., Ren, D., White, F.A., Miller, R.J., 2009. Visualization of chemokine receptor activation in transgenic mice reveals peripheral activation of CCR2 receptors in states of neuropathic pain. The Journal of neuroscience : the official journal of the Society for Neuroscience 29 , 8051-8062.

Jung, H., Miller, R.J., 2008. Activation of the nuclear factor of activated T-cells (NFAT) mediates upregulation of CCR2 chemokine receptors in dorsal root ganglion (DRG) neurons: a possible mechanism for activity-dependent transcription in DRG neurons in association with neuropathic pain. Molecular and cellular neurosciences 37, 170-177.

Jung, H., Toth, P.T., White, F.A., Miller, R.J., 2008. Monocyte chemoattractant protein-1 functions as a neuromodulator in dorsal root ganglia neurons. Journal of neurochemistry 104, 254-263.

Kao, D.J., Li, A.H., Chen, J.C., Luo, R.S., Chen, Y.L., Lu, J.C., Wang, H.L., 2012. CC chemokine ligand 2 upregulates the current density and expression of TRPV1 channels and Nav1.8 sodium channels in dorsal root ganglion neurons. Journal of neuroinflammation 9, 189.

Kiguchi, N., Kobayashi, Y., Saika, F., Kishioka, S., 2013. Epigenetic upregulation of CCL2 and CCL3 via histone modifications in infiltrating macrophages after peripheral nerve injury. Cytokine 64, 666-672.

LaMotte, R.H., 2016. Allergic Contact Dermatitis: A Model of Inflammatory Itch and Pain in Human and Mouse. 
Advances in experimental medicine and biology 904, 23-32.

Liu, F., Xu, L., Chen, N., Zhou, M., Li, C., Yang, Q., Xie, Y., Huang, Y., Ma, C., 2017. Neuronal Fc-epsilon receptor I contributes to antigen-evoked pruritus in a murine model of ocular allergy. Brain Behav Immun 61, 165-175.

Liu, Q., Sikand, P., Ma, C., Tang, Z., Han, L., Li, Z., Sun, S., LaMotte, R.H., Dong, X., 2012. Mechanisms of itch evoked by beta-alanine. The Journal of neuroscience : the official journal of the Society for Neuroscience 32, 14532-14537.

Loetscher, P., Seitz, M., Clark-Lewis, I., Baggiolini, M., Moser, B., 1994. Monocyte chemotactic proteins MCP-1, MCP-2, and MCP-3 are major attractants for human CD4+ and CD8+ T lymphocytes. FASEB journal : official publication of the Federation of American Societies for Experimental Biology 8, 1055-1060.

Miller, R.E., Tran, P.B., Das, R., Ghoreishi-Haack, N., Ren, D.J., Miller, R.J., Malfait, A.M., 2012. CCR2 chemokine receptor signaling mediates pain in experimental osteoarthritis. P Natl Acad Sci USA 109, 20602-20607.

Mirzadegan, T., Diehl, F., Ebi, B., Bhakta, S., Polsky, I., McCarley, D., Mulkins, M., Weatherhead, G.S., Lapierre, J.M., Dankwardt, J., Morgans, D., Jr., Wilhelm, R., Jarnagin, K., 2000. Identification of the binding site for a novel class of CCR2b chemokine receptor antagonists: binding to a common chemokine receptor motif within the helical bundle. The Journal of biological chemistry 275, 25562-25571.

Mitsui, G., Mitsui, K., Hirano, T., Ohara, O., Kato, M., Niwano, Y., 2003. Kinetic profiles of sequential gene expressions for chemokines in mice with contact hypersensitivity. Immunology letters 86, 191-197.

Mizumoto, N., Iwabichi, K., Nakamura, H., Ato, M., Shibaki, A., Kawashima, T., Kobayashi, H., Iwabuchi, C., Ohkawara, A., Onoe, K., 2001. Enhanced contact hypersensitivity in human monocyte chemoattractant protein-1 transgenic mouse. Immunobiology 204, 477-493.

Nakamura, K., Williams, I.R., Kupper, T.S., 1995. Keratinocyte-derived monocyte chemoattractant protein 1 (MCP-1): analysis in a transgenic model demonstrates MCP-1 can recruit dendritic and Langerhans cells to skin. The Journal of investigative dermatology 105, 635-643.

Oh, S.B., Tran, P.B., Gillard, S.E., Hurley, R.W., Hammond, D.L., Miller, R.J., 2001. Chemokines and glycoprotein 120 produce pain hypersensitivity by directly exciting primary nociceptive neurons. The Journal of neuroscience : the official journal of the Society for Neuroscience 21, 5027-5035.

Qu, L., Fan, N., Ma, C., Wang, T., Han, L., Fu, K., Wang, Y., Shimada, S.G., Dong, X., LaMotte, R.H., 2014. Enhanced excitability of MRGPRA3- and MRGPRD-positive nociceptors in a model of inflammatory itch and pain. Brain : a journal of neurology 137, 1039-1050.

Qu, L., Zhang, P., LaMotte, R.H., Ma, C., 2011a. Neuronal Fc-gamma receptor I mediated excitatory effects of IgG immune complex on rat dorsal root ganglion neurons. Brain Behav Immun 25, 1399-1407.

Qu, L.T., Fu, K., Yang, J., Shimada, S.G., LaMotte, R.H., 2015. CXCR3 chemokine receptor signaling mediates itch in experimental allergic contact dermatitis. Pain 156, 1737-1746.

Qu, L.T., Li, Y.M., Pan, X.H., Zhang, P., LaMotte, R.H., Ma, C., 2012. Transient Receptor Potential Canonical 3 (TRPC3) Is Required for IgG Immune Complex-Induced Excitation of the Rat Dorsal Root Ganglion Neurons. Journal of Neuroscience 32, 9554-9562.

Qu, L.T., Zhang, P., LaMotte, R.H., Ma, C., 2011b. Neuronal Fc-gamma receptor I mediated excitatory effects of IgG immune complex on rat dorsal root ganglion neurons. Brain Behav Immun 25, 1399-1407.

Sebastiani, S., Albanesi, C., De, P.O., Puddu, P., Cavani, A., Girolomoni, G., 2002. The role of chemokines in allergic contact dermatitis. Archives of dermatological research 293, 552-559.

Serrano, A., Pare, M., McIntosh, F., Elmes, S.J., Martino, G., Jomphe, C., Lessard, E., Lembo, P.M., Vaillancourt, F., Perkins, M.N., Cao, C.Q., 2010. Blocking spinal CCR2 with AZ889 reversed hyperalgesia in a 
model of neuropathic pain. Molecular pain 6, 90.

Shimada, S.G., LaMotte, R.H., 2008a. Behavioral differentiation between itch and pain in mouse. Pain 139, 681-687.

Shimada, S.G., LaMotte, R.H., 2008b. Behavioral differentiation between itch and pain in mouse. Pain 139, 681-687.

Subang, M.C., Richardson, P.M., 2001. Influence of injury and cytokines on synthesis of monocyte chemoattractant protein-1 mRNA in peripheral nervous tissue. The European journal of neuroscience 13, 521-528.

Sun, J.H., Yang, B., Donnelly, D.F., Ma, C., LaMotte, R.H., 2006. MCP-1 enhances excitability of nociceptive neurons in chronically compressed dorsal root ganglia. Journal of neurophysiology 96, 2189-2199.

Takeda, M., Nasu, M., Kanazawa, T., Takahashi, M., Shimazu, Y., 2018. Chemokine ligand 2/chemokine receptor 2 signaling in the trigeminal ganglia contributes to inflammatory hyperalgesia in rats. Neuroscience research 128, 25-32.

Tanaka, T., Minami, M., Nakagawa, T., Satoh, M., 2004. Enhanced production of monocyte chemoattractant protein-1 in the dorsal root ganglia in a rat model of neuropathic pain: possible involvement in the development of neuropathic pain. Neuroscience research 48, 463-469.

Thacker, M.A., Clark, A.K., Bishop, T., Grist, J., Yip, P.K., Moon, L.D., Thompson, S.W., Marchand, F., McMahon, S.B., 2009. CCL2 is a key mediator of microglia activation in neuropathic pain states. European journal of pain 13, 263-272.

Tofaris, G.K., Patterson, P.H., Jessen, K.R., Mirsky, R., 2002. Denervated Schwann cells attract macrophages by secretion of leukemia inhibitory factor (LIF) and monocyte chemoattractant protein-1 in a process regulated by interleukin-6 and LIF. The Journal of neuroscience : the official journal of the Society for Neuroscience 22, 6696-6703.

Ueda, A., Okuda, K., Ohno, S., Shirai, A., Igarashi, T., Matsunaga, K., Fukushima, J., Kawamoto, S., Ishigatsubo, Y., Okubo, T., 1994. NF-kappa B and Sp1 regulate transcription of the human monocyte chemoattractant protein-1 gene. Journal of immunology 153, 2052-2063.

Wang, C.H., Zou, L.J., Zhang, Y.L., Jiao, Y.F., Sun, J.H., 2010. The excitatory effects of the chemokine CCL2 on DRG somata are greater after an injury of the ganglion than after an injury of the spinal or peripheral nerve. Neuroscience letters 475, 48-52.

White, F.A., Sun, J., Waters, S.M., Ma, C., Ren, D., Ripsch, M., Steflik, J., Cortright, D.N., Lamotte, R.H., Miller, R.J., 2005. Excitatory monocyte chemoattractant protein-1 signaling is up-regulated in sensory neurons after chronic compression of the dorsal root ganglion. Proc Natl Acad Sci U S A 102, 14092-14097.

Wilson, S.R., Gerhold, K.A., Bifolck-Fisher, A., Liu, Q., Patel, K.N., Dong, X.Z., Bautista, D.M., 2011. TRPA1 is required for histamine-independent, Mas-related G protein-coupled receptor-mediated itch. Nat Neurosci 14, 595-U582.

Yu, X., Barnhill, R.L., Graves, D.T., 1994. Expression of monocyte chemoattractant protein-1 in delayed type hypersensitivity reactions in the skin. Laboratory investigation; a journal of technical methods and pathology 71 , 226-235.

Zhang, H., Boyette-Davis, J.A., Kosturakis, A.K., Li, Y., Yoon, S.Y., Walters, E.T., Dougherty, P.M., 2013. Induction of monocyte chemoattractant protein-1 (MCP-1) and its receptor CCR2 in primary sensory neurons contributes to paclitaxel-induced peripheral neuropathy. The journal of pain : official journal of the American Pain Society 14, 1031-1044.

Zhang, J., De Koninck, Y., 2006. Spatial and temporal relationship between monocyte chemoattractant protein-1 expression and spinal glial activation following peripheral nerve injury. Journal of neurochemistry 97, 772-783. 
Zhou, Y., Tang, H., Liu, J., Dong, J., Xiong, H., 2011. Chemokine CCL2 modulation of neuronal excitability and synaptic transmission in rat hippocampal slices. Journal of neurochemistry 116, 406-414.

Zylka, M.J., Rice, F.L., Anderson, D.J., 2005. Topographically distinct epidermal nociceptive circuits revealed by axonal tracers targeted to Mrgprd. Neuron 45, 17-25. 


\section{Figure Legends}

Figure 1. Upregulation of the expression of CCL2 and CCR2 in the DRG in CHS mice. A. qRT-PCR revealed a significant increase in mRNA expression levels of CCL2 and CCR2 in L3-L5 DRG for CHS (SADBE- treated) vs control (vehicle-treated) mice 24 hours after the second challenge ( $\mathrm{n}=5$ mice/group for CCL2, $n=3$ mice/group for CCR2). B. Western blot revealed a significant increase in the levels of CCL2 and CCR2 protein expression in L3-L5 DRG for CHS vs control mice 24 hours after the second challenge ( $\mathrm{n}=3$ mice/group). C. The representative gel bands of CCL2 and CCR2 protein from control and CHS mice. D. Immunofluorescence staining showed a significantly higher percentage of CCL2- and CCR2-immunopositive DRG neurons in CHS mice compared with that in control mice ( $\mathrm{n}=3$ mice/group). E. Frequency distribution of different cell sizes of CCL2/CCR2-immunopositive DRG neurons in CHS mice. F. Percentages of CCR2 positive DRG neurons that express IB4 and TRPV1 in CHS mice. G-J. Typical microscopic images of immunofluorescence staining for CCL2 (G and I) and CCR2 (H and J) from control and CHS mice. K and L. CCR2 was found co-expressed with IB4 (K) and TRPV1(L) in some DRG neurons in CHS mice. Arrows indicate immunopositive neurons. Scale bar: $25 \mu \mathrm{m} . * p<0.05$, $* * * p<0.001$, CHS vs control, Student's t-test.

Figure 2. CHS increased the incidence and magnitude of CCL2-induced $\mathrm{Ca}^{2+}$ responses in DRG neurons with pruriceptive or nociceptive properties. A and B. Cultured cutaneous (DiI-labeled) DRG neurons isolated from control (A) and CHS (B) mice were exposed to 
CCL2 (50 nM, 2 min), followed by histamine (His; $100 \mu \mathrm{M}, 30 \mathrm{~s}$ ), capsaicin (CAP; $1 \mu \mathrm{M}, 10$ s) and $\mathrm{KCl}(50 \mathrm{mM}, 5 \mathrm{~s})$, and analyzed by Fura-2 ratiometric calcium imaging (representative traces). Black bars above the traces show the duration of chemical application. $\mathbf{C}$ and D. The proportion of CCL2-responsive cutaneous DRG neurons and the mean magnitude of CCL2-induced $\mathrm{Ca}^{2+}$ response were significantly higher for CHS mice than for acetone-treated control mice. $\mathbf{E}$ and $\mathbf{F}$. The percentage of MrgprA $3^{+}$neurons that responded to CCL2 and the mean magnitude of $\mathrm{Ca}^{2+}$ signal in the responsive neurons were significantly greater in CHS than that in control mice. $\mathbf{G}$ and $\mathbf{H}$. The percentage of $\mathrm{MrgprD}^{+}$neurons that responded to CCL2 and the mean magnitude of $\mathrm{Ca}^{2+}$ signal in the responsive neurons were significantly greater in CHS than that in control mice. Numbers of neurons tested are given in parentheses. ${ }^{* *} p<0.01$ versus control, Chi-square test $(\mathrm{C}, \mathrm{E}$ and $\mathrm{G}) ;{ }^{*} p<0.05$ versus control, Student's t-test (D, F and H).

Figure 3. Neuronal CCR2 is required for CCL2-induced $\left[\mathrm{Ca}^{2+}\right]_{\mathrm{i}}$ responses in cutaneous DRG neurons. A and B. Representative traces of $\mathrm{Ca}^{2+}$ responses evoked by CCL2 ( $50 \mathrm{nM}, 2 \mathrm{~min}$ ) in the presence of a specific CCR2 antagonist RS504393 (10 $\mu \mathrm{M}$ in a vehicle of $0.1 \%$ DMSO) vs in the presence of the vehicle alone. C and D. The percentage of CCL2-responsive neurons and the mean magnitude of CCL2-evoked $\mathrm{Ca}^{2+}$ response were significantly attenuated by pretreatment with RS504393 but not vehicle. The neurons tested were all from CHS mice. The numbers of neurons tested are given in parentheses. $* p<0.05$ versus vehicle, Chi-square test (C); *p $<0.05$ versus vehicle, Student's t-test (D). 
Figure 4. CCL2 increased the excitability of cutaneous DRG neurons after CHS. A and D. Representative whole-cell current-clamp recordings of CCL2-induced membrane potential depolarization with (A) and without (D) AP discharges. Black bars above the traces show the timing of CCL2 (50 nM; $2 \mathrm{~min})$ application. B. The percentage of neurons responsive to CCL2 during whole-cell current-clamp recordings in CHS mice and acetone-treated control mice. $\mathbf{C}, \mathbf{E}$ and $\mathbf{F}$. Mean resting membrane potential, input resistance, and rheobase during application of vehicle (HEPES buffer) and CCL2 in cutaneous DRG neurons from CHS mice. G. Typical whole-cell current-clamp recordings during CCL2 application in the presence of RS504393 $(10 \mu \mathrm{M})$. H and I. Pretreatment with RS504393 decreased the percentage of neurons that responded to CCL2 $(\mathrm{H})$ and significantly reduced the mean magnitude of CCL2-induced membrane depolarization (I). Numbers of neurons responding and/or tested is given in parentheses. ${ }^{*} p<0.05,{ }^{*} p<<0.01$ versus vehicle, paired t test $(\mathrm{C}, \mathrm{E}$ and $\mathrm{F}) ;{ }^{*} p<$ 0.05 versus control, Student's t-test (I).

Figure 5. CCL2/CCR2 signaling mediated itch- and pain-like behaviors in CHS mice. A and B. The effects of CHS on the cheek on spontaneous and CCL2-evoked site-directed scratching and wiping (itch- and pain-like behaviors, respectively) 24 hours after the second challenge with SADBE (CHS, closed bars) or acetone vehicle (control, open bars). CHS mice displayed a significant increase in site-directed scratching and wiping compared with control mice. Intradermal injection of CCL2 $(1 \mu \mathrm{g} / 10 \mu \mathrm{l}$ in PBS vehicle) into the cheek of CHS mice significantly increased the site-directed scratching (A) and wiping (D) compared with the effects of injecting the PBS vehicle alone (Veh1). When CCL2 was injected into the cheek of 
control mice, there were no significant differences in effects from injecting PBS vehicle alone. The CCL2-evoked scratching and wiping in the cheek challenged with SADBE was significantly reduced by intraperitoneal pre-injection of RS504393 (5 mg/kg) but not its DMSO vehicle (Veh2). There were no significant differences (ns) in either scratching bouts or number of wipes between PBS (Veh1)-treated and RS504393-treated CHS mice. The number of animals tested is given in parentheses. $* p<0.05, * * * p<0.001$, Student's t-test. 

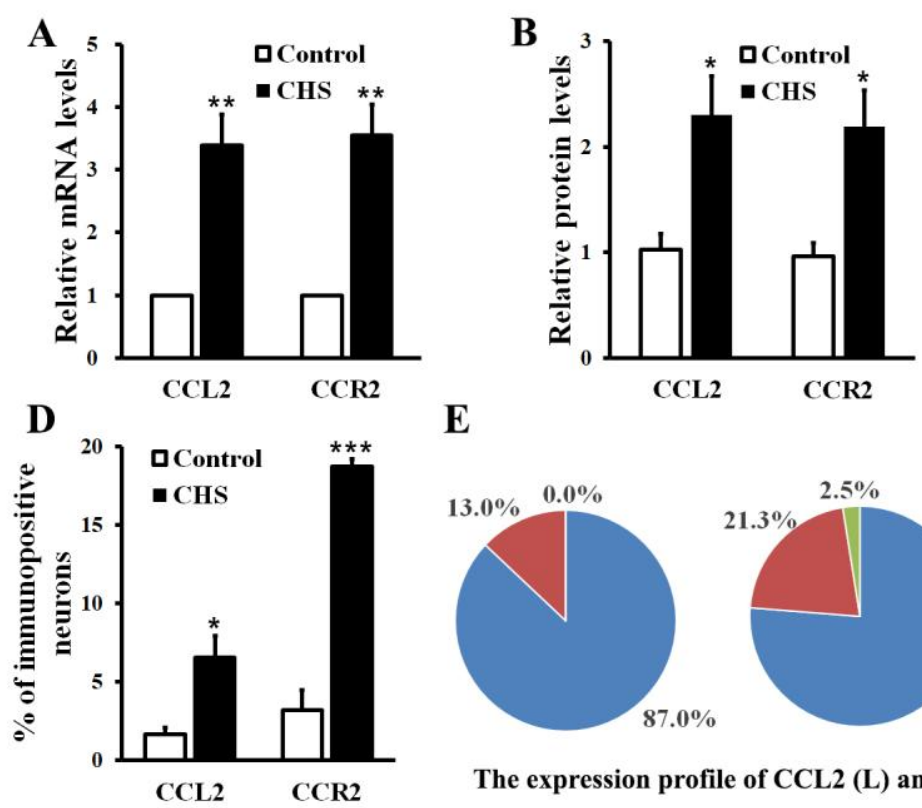

C

E

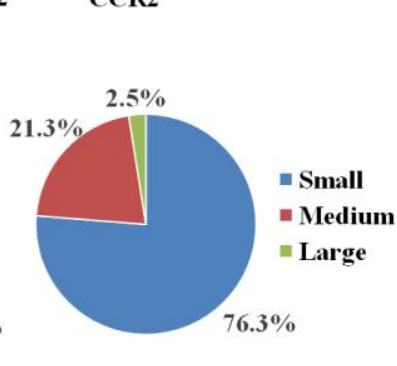

The expression profile of CCL2 (L) and CCR2 (R)
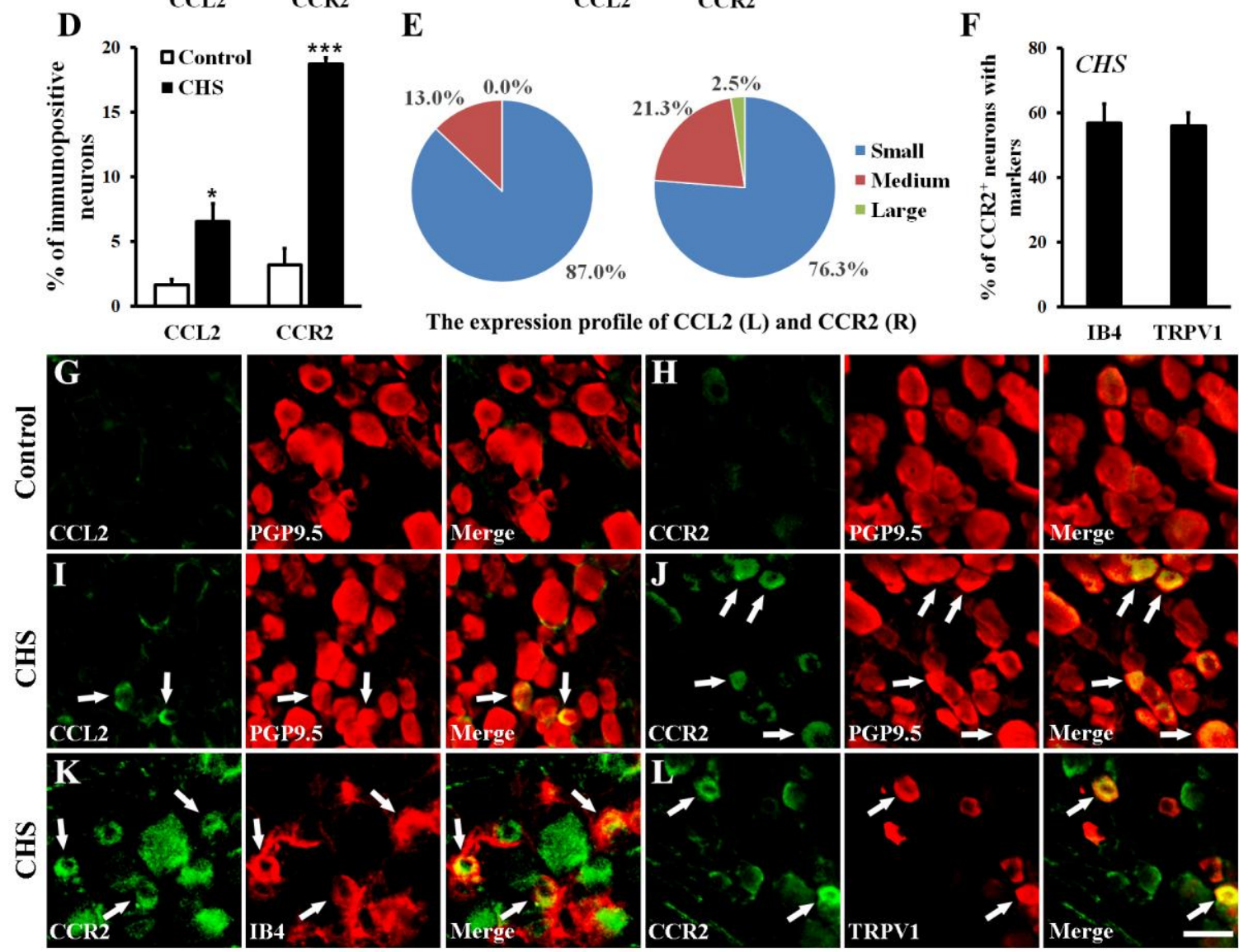

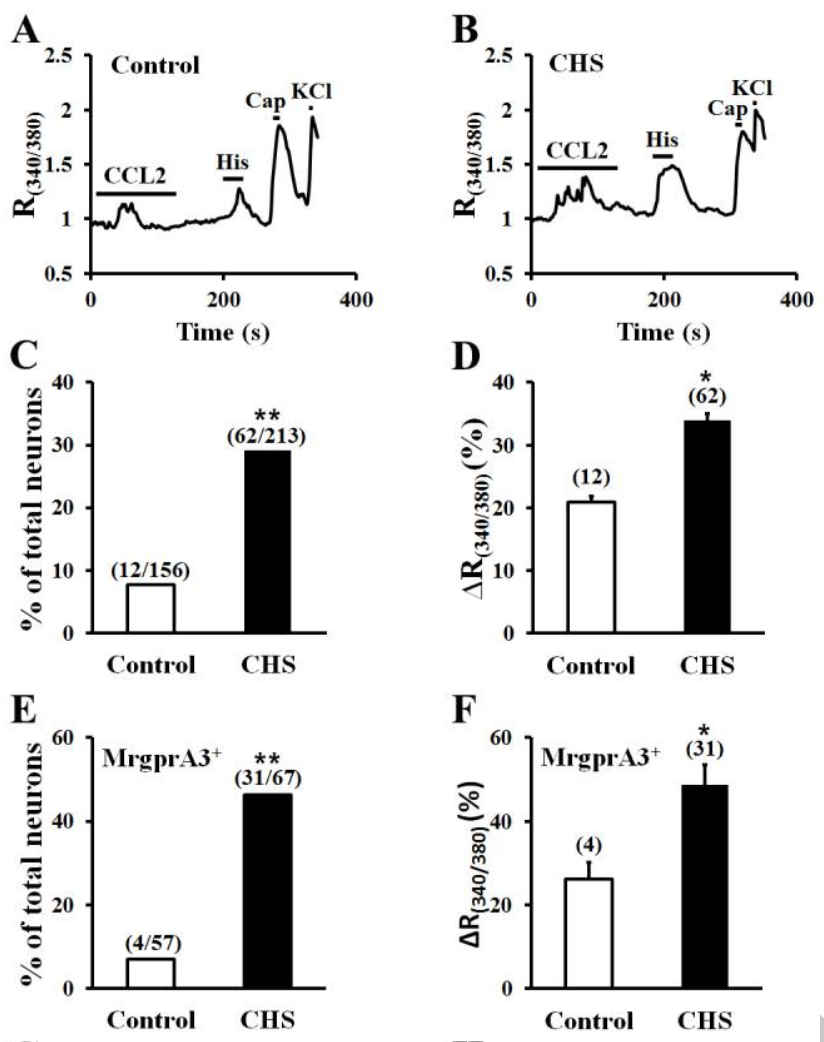

F
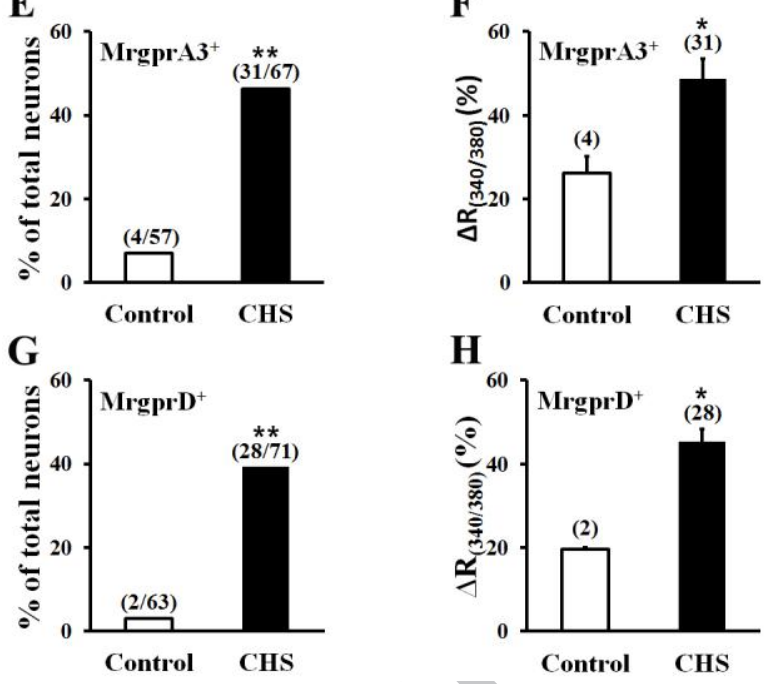

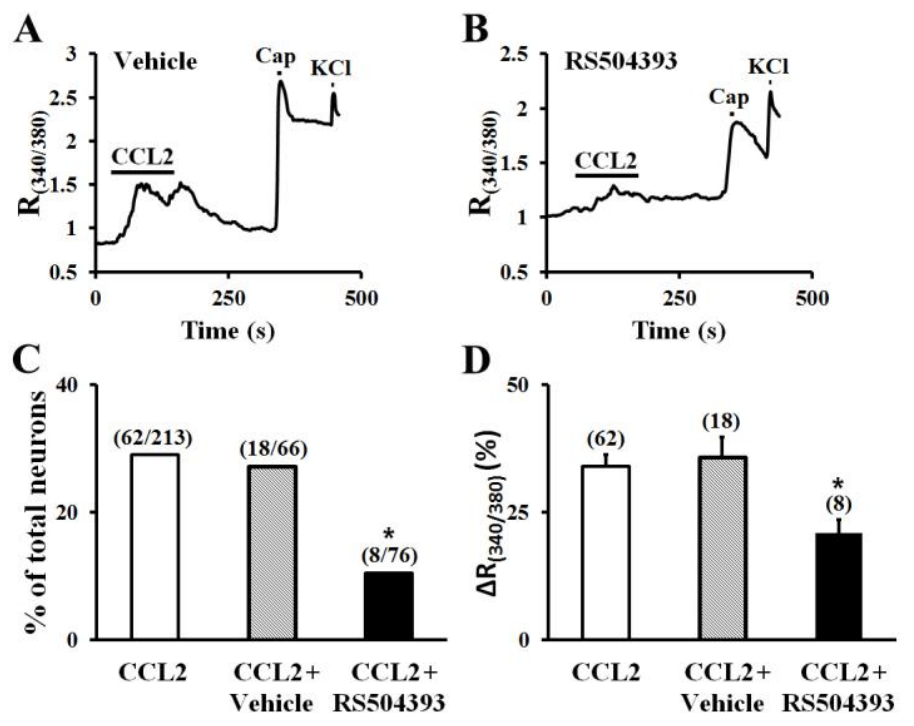

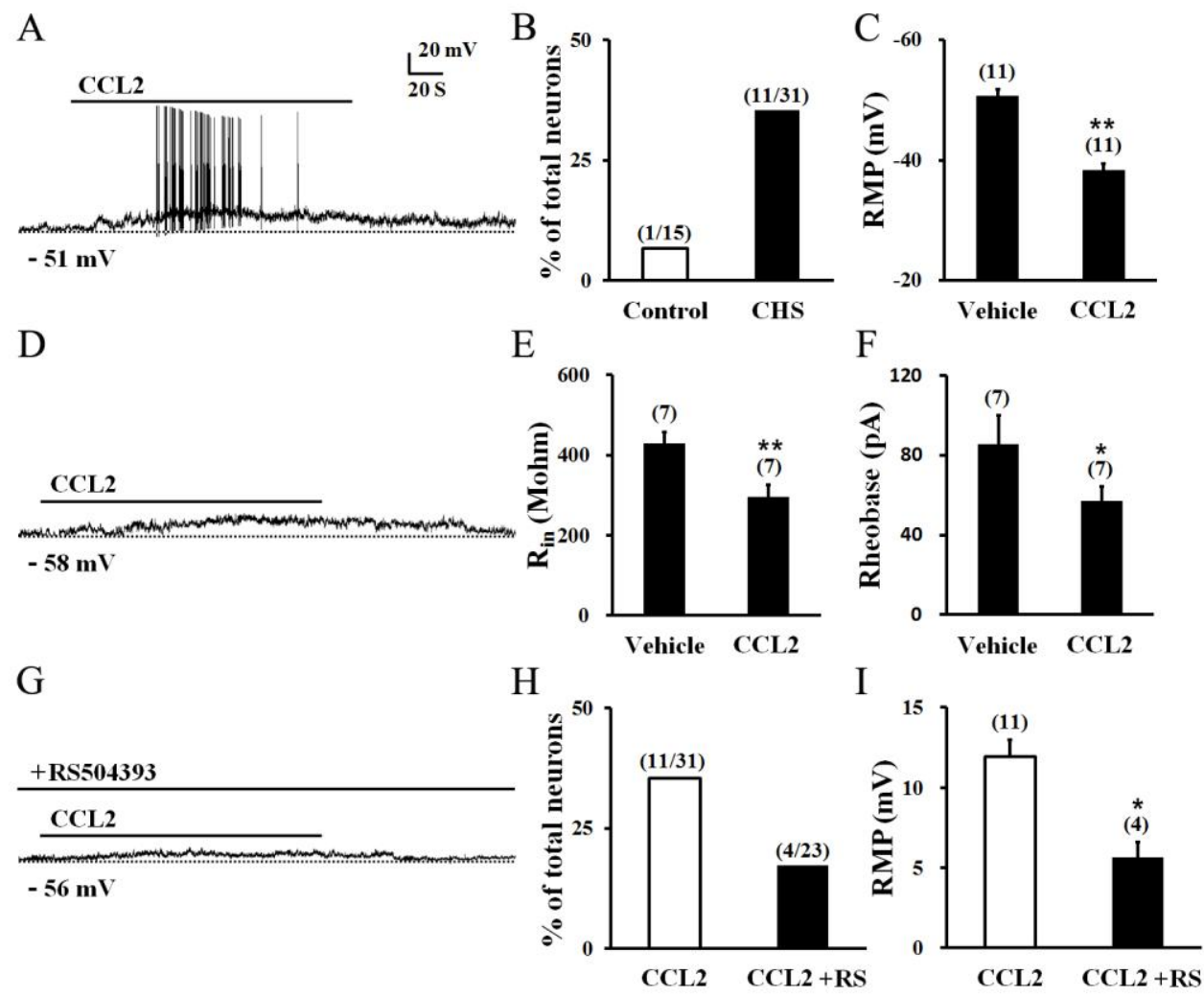
A

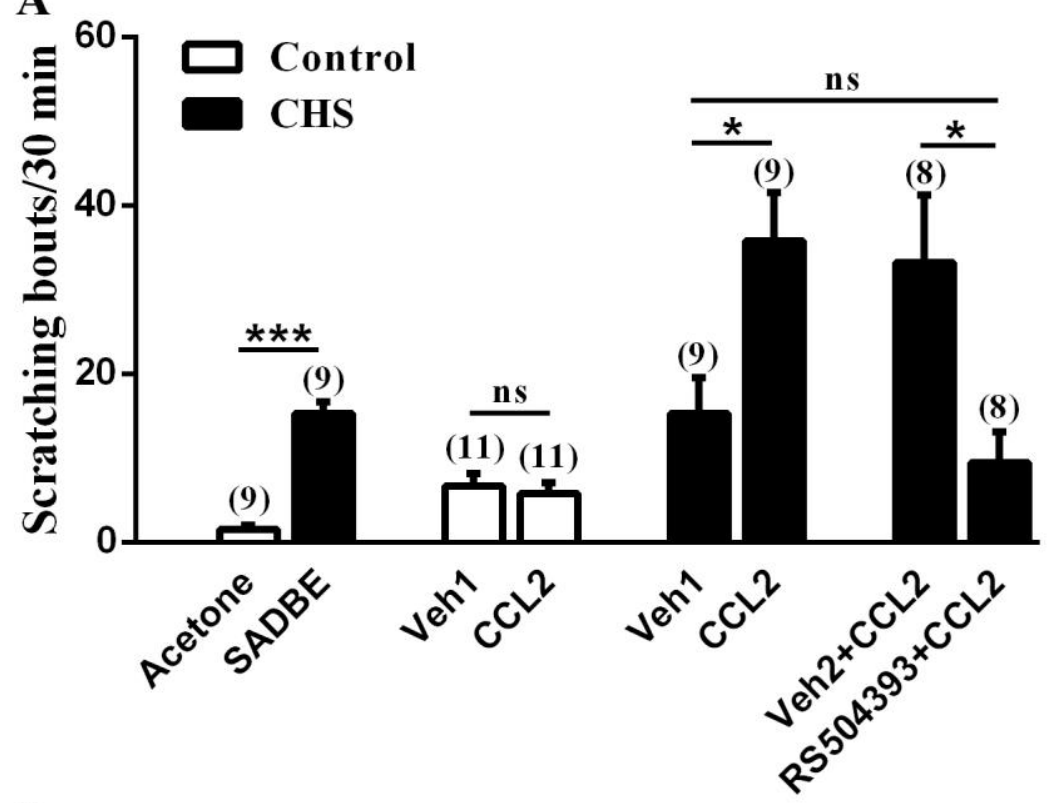

B

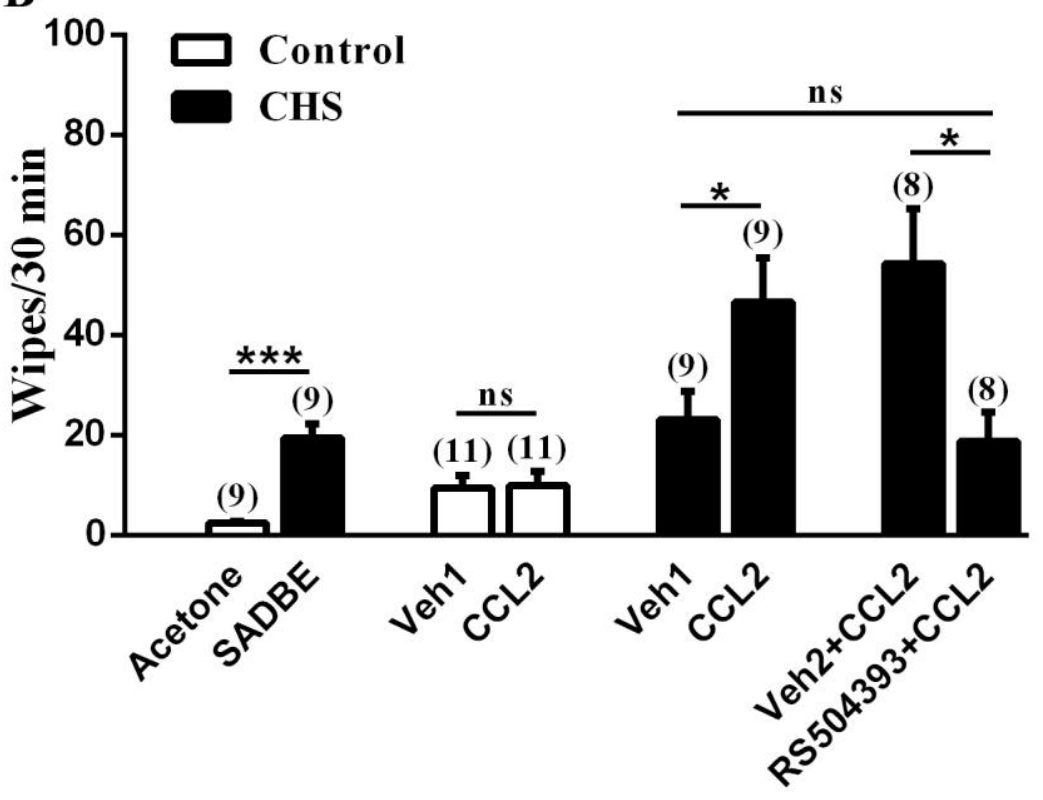




\section{Highlights}

- Contact hypersensitivity (CHS), a murine model of allergic contact dermatitis, upregulated CCL2/MCP-1 and CCR2 in nociceptors.

- CCL2 injected into CHS site evoked site-directed itch- and pain-like behaviors.

- CCL2 activated nociceptive dorsal root ganglion neurons innervating $\mathrm{CHS}$ site.

- A CCR2 antagonist decreased these behavioral and neuronal responses.

- Targeting CCL2/CCR2 signaling might treat allergic itch and pain in humans. 